\title{
Hypoxia Alters Early Gestation Human Cytotrophoblast Differentiation/Invasion In Vitro and Models the Placental Defects that Occur in Preeclampsia
}

\author{
Olga Genbacev, ${ }^{*}$ Rebecca Joslin, ${ }^{\star}$ Caroline H. Damsky, ${ }^{\star \ddagger}$ Bruno M. Polliotti, ${ }^{\top}$ and Susan J. Fisher ${ }^{\star \star \S} \|$ \\ Departments of *Stomatology, ${ }^{\ddagger}$ Anatomy, ${ }^{\S}$ Pharmaceutical Chemistry, and $\|^{\|}$Obstetrics, Gynecology and Reproductive Sciences, \\ University of California San Francisco, San Francisco, California 94143-0512; and "Division of Infectious Diseases, Epidemiology \\ and Immunology, Emory University School of Medicine, Atlanta, Georgia 30303
}

\begin{abstract}
During normal human pregnancy a subpopulation of fetal cytotrophoblast stem cells differentiate and invade the uterus and its arterioles. In the pregnancy disease preeclampsia, cytotrophoblast differentiation is abnormal and invasion is shallow. Thus, the placenta is relatively hypoxic. We investigated whether lowering oxygen tension affects cytotrophoblast differentiation and invasion. Previously we showed that when early gestation cytotrophoblast stem cells are cultured under standard conditions $\left(20 \% \mathrm{O}_{2}\right)$ they differentiate/invade, replicating many aspects of the in vivo process. Specifically, the cells proliferate at a low rate and rapidly invade extracellular matrix (ECM) substrates, a phenomenon that requires switching their repertoire of integrin cellECM receptors, which are stage-specific antigens that mark specific transitions in the differentiation process. In this study we found that lowering oxygen tension to $2 \%$ did not change many of the cells' basic processes. However, there was a marked increase in their incorporation of $\left[{ }^{3} \mathrm{H}\right]$ thymidine and 5-bromo-2' -deoxyuridine (BrdU). Moreover, they failed to invade ECM substrates, due at least in part to their inability to completely switch their integrin repertoire. These changes mimic many of the alterations in cytotrophoblast differentiation/invasion that occur in preeclampsia, suggesting that oxygen tension plays an important role in regulating these processes in vivo. (J. Clin. Invest. 1996. 97: 540-550.) Key words: trophoblast • preeclampsia • hypoxia • invasion • integrins
\end{abstract}

\section{Introduction}

Normal development of the placenta depends on differentiation of its specialized epithelial cells, termed trophoblasts (reviewed in 1,2). Human cytotrophoblast stem cells follow one of two differentiation pathways. Those in floating villi detach from their basement membrane and fuse to form a syncytial layer that is in direct contact with maternal blood. These syncytiotrophoblasts play an important role in nutrient, waste, and gas exchange. In anchoring villi, cytotrophoblasts also

Address correspondence to Susan Fisher, Department of Stomatology, HSW 604, 513 Parnassus Avenue, University of California, San Francisco, CA 94143-0512. Phone: 415-476-5297; Fax: 415-476-4204; E-mail: sfisher@cgl.ucsf.edu

Received for publication 18 April 1995 and accepted in revised form 29 September 1995.

J. Clin. Invest.

(C) The American Society for Clinical Investigation, Inc. 0021-9738/96/01/540/11 \$2.00

Volume 97, Number 2, January 1996, 540-550 fuse, but at specific locations many aggregate and form columns of mononuclear cells that attach to and then invade the decidualized endometrium and the first third of the myometrium (interstitial invasion), as well as the associated portions of uterine (spiral) arterioles (endovascular invasion). Cytotrophoblast invasion anchors the fetus to the mother and creates the large-diameter, low-resistance vessels that carry blood to the floating villi at the maternal-fetal interface.

We and others have used two approaches to study the differentiation process that results in human cytotrophoblast invasion of the uterus. First, analysis of tissue sections that contain both floating and anchoring villi allows descriptive studies of cytotrophoblast protein and RNA expression in vivo $(3,4)$. Second, we discovered that removing early gestation cytotrophoblast stem cells from their basement membranes and plating them on extracellular matrices $(\mathrm{ECMs})^{1}$ reprograms their fate such that they differentiate along the invasive pathway, rather than fuse to form syncytium (5-10). This in vitro model can be used to study mechanisms involved in the invasion process.

By using this combination of approaches, we showed that human cytotrophoblast invasion is accompanied by a reduction in the cells' proliferative capacity and requires the regulated expression of either proteinases or adhesion molecules. As they acquire an invasive phenotype, cytotrophoblasts produce and activate the $92-\mathrm{kD}$ type IV collagenase, matrix metalloproteinase 9 (5). They also switch their repertoire of integrin cell-ECM adhesion receptors (3). In the first trimester human placenta, $\alpha 6$ integrins (laminin receptors) are localized primarily to cytotrophoblast stem cells, and their expression is downregulated during invasion. In contrast, the expression of integrins $\alpha 5 \beta 1$ (fibronectin receptor) and $\alpha 1 \beta 1$ (receptor for collagens I and IV and laminin) is sequentially upregulated in differentiating and invading cytotrophoblasts. By using reagents that specifically inhibit either matrix metalloproteinase- 9 or cytotrophoblast integrin functions, we showed that matrix metalloproteinase- 9 and $\alpha 1 \beta 1$ promote invasion in vitro, whereas $\alpha 5 \beta 1$ integrin inhibits this process $(6,7,9)$. Thus, a balance between forces that promote or inhibit invasion is critical to placentation.

We have been interested in diseases of pregnancy that are associated with abnormal placentation as a means of understanding the in vivo relevance of our in vitro function perturbation experiments. Preeclampsia, which affects $7-10 \%$ of all first-time pregnancies (reviewed in reference 11), is one such syndrome. Compared with normal pregnancy, cytotrophoblasts in preeclampsia show an increased ability to proliferate

1. Abbreviations used in this paper: $\mathrm{BrdU}, 5$-bromo-2'-deoxyuridine; ECM, extracellular matrix; hCG, human chorionic gonadotropin; hPL, human placental lactogen. 
(12). In addition, invasion is shallow and fewer arterioles are breached, an important factor with regard to the reduction in uteroplacental blood flow observed in this syndrome (13). How abnormal placentation translates into the clinical presentation of the disease, which includes fetal intrauterine growth retardation and maternal hypertension and proteinuria, is not yet clear $(11,14)$. However, work from our laboratory showed that lack of invasion is associated with specific alterations in the cytotrophoblasts' ability to differentiate. They express integrin $\alpha 5 \beta 1$ but not $\alpha 1 \beta 1(15,16)$, an adhesive phenotype which our in vitro experiments predict would restrain invasion.

Together, these results suggest that oxygen tension could regulate the cytotrophoblasts' ability to differentiate and, as a consequence, to express proteins that are critical to the invasion process. In mammalian cells that have been studied in this context (e.g., endothelial cells, tumor spheroids) hypoxia upregulates the expression of stress (oxygen-regulated proteins), heat shock, and glucose-regulated proteins, as well as cytokines and growth factors (17-21). These include erythropoietin (22, 23), PDGF B chain (24), endothelin (25), IL-1 $\alpha$ (26), IL-8 (27), ornithine decarboxylase (28), vascular endothelial growth factor (29), glyceraldehyde-3-phosphate dehydrogenase (30), xanthine dehydrogenase/xanthine oxidase (31), and metallothionein IIA (32).

The cis-acting DNA sequences and the trans-acting transcription factors that regulate the expression of these hypoxiainduced proteins are beginning to be elucidated. For example, hypoxia-inducible factor 1 , a nuclear protein whose DNAbinding activity is induced in hypoxia, upregulates erythropoietin production by binding to an enhancer element (5'-TACGTGCT- $\left.3^{\prime}\right)$ in the $3^{\prime}$ region of this gene $(33,34)$. Hypoxiainducible factor 1 also induces transcription of glycolytic enzymes, which are important to the cells' ability to switch from aerobic respiration to glycolysis for energy production (35). The expression and/or activity of several other transcription factors, including Fos and Jun (components of the AP-1 complex; 36), nuclear factor $\mathrm{\kappa B}(37)$, and the heat shock transcription factor (38), also increase in hypoxia.

These studies suggest that hypoxia can specifically alter a cell's gene expression and protein repertoire. Here we report the results of experiments in which we analyzed the effects of varying the oxygen content of the culture atmosphere on differentiation/invasion of early gestation cytotrophoblasts in vitro. The impetus for these experiments was the dramatic changes in oxygen content of the placental environment that normally occur during early gestation. Namely, before the tenth week of pregnancy there is little blood flow to the intervillous space, due to the fact that cytotrophoblast invasion is largely interstitial, rather than endovascular. As a result, the placenta proper is relatively hypoxic. Rodesch et al. (39) used a polarographic oxygen electrode to show that the mean oxygen pressure of the intervillous space is $17.9 \pm(\mathrm{SD}) 6.9 \mathrm{mmHg}$ at $8-10$ wk gestation as compared with $39.6 \pm 12.3$ in the endometrium. By 12-13 wk the oxygen pressure in the intervillous space is $60.7 \pm 8.5 \mathrm{mmHg}$, a reflection of the fact that cytotrophoblasts are beginning to substantially remodel the spiral arterioles. Consequently, blood flow to the intervillous space increases dramatically. Presumably the most invasive cytotrophoblasts, e.g., those that line these arterioles, are exposed to oxygen concentrations similar to those of arterial blood $(95-100 \mathrm{mmHg})$.
Preeclampsia is associated with failure of cytotrophoblasts to invade the spiral arterioles (15). We hypothesized that in this disease the events that normally take place during the first trimester of pregnancy, which convert the maternal-fetal interface from a relatively hypoxic environment to one that is relatively well oxygenated, fail to occur. Consequently, cytotrophoblast stem cells remain in a relatively hypoxic environment. We were interested in determining whether this could affect the cells' ability to differentiate, a prerequisite for invasion. Our findings suggest this is the case. Specifically, we found that hypoxia affects progression of cytotrophoblasts through the cell cycle. In addition, their invasiveness is greatly reduced due at least in part to alterations in integrin cell-ECM receptor expression. Together, these results suggest that hypoxia alters the balance between proliferation and differentiation of cytotrophoblasts and initiates a feedback mechanism that inhibits their differentiation and invasion, thus setting the stage for later pregnancy complications such as preeclampsia.

\section{Methods}

Cytotrophoblast isolation and culture. Placentas were obtained immediately after first (10-12 wk) and second (16-24 wk) trimester terminations. Cytotrophoblasts were isolated from pools of multiple placentas by published methods (6). In all cases, remaining leukocytes were removed by using an antibody to $\mathrm{CD}-45$, a protein tyrosine phosphatase found on bone marrow-derived cells (40), coupled to magnetic beads. Previous work from this laboratory showed that this method removes contaminating nontrophoblast cells, as demonstrated by the absence of classical HLA class I antigens (41). The resulting cells were plated on Matrigel-coated substrates (Collaborative Biomedical Products, Bedford, MA) and cultured in DME H21 MEM containing 2\% Nutridoma (Boehringer Mannheim Biochemicals, Indianapolis, IN) and $50 \mu \mathrm{g} / \mathrm{ml}$ gentamicin (6).

Cytotrophoblasts were either maintained under standard tissue culture conditions $\left(5 \% \mathrm{CO}_{2} / 95 \%\right.$ air) or placed in a Bactron anaerobic incubator (Sheldon Manufacturing Inc., Cornelius, OR) where they were maintained in a $2 \% \mathrm{O}_{2} / 93 \% \mathrm{~N}_{2} / 5 \% \mathrm{CO}_{2}$ environment. The incubator was located inside a chamber that allowed manipulation of the cells in the same atmosphere. In experiments in which we used three different concentrations of oxygen (2, 8, and 20\%), cells maintained in $8 \%$ oxygen were cultured in a Modular incubator chamber (Billups-Rothenberg, Del Mar, CA). The chamber was filled with a mixture of $\mathrm{O}_{2}, \mathrm{~N}_{2}$, and $\mathrm{CO}_{2}$ to achieve a final oxygen concentration of $8 \%$ and a final $\mathrm{CO}_{2}$ concentration of $5 \%$. Dissolved $\mathrm{O}_{2}$ at the cellmedium interface, measured using microoxygen electrodes (MI-730; Microelectrode Inc., Londonderry, $\mathrm{NH}$ ), was $20 \%$ (98 $\mathrm{mmHg}$ ) under standard tissue culture conditions, $8 \%$ in the Modular incubator chamber $(56 \mathrm{mmHg})$, and $2 \%(14 \mathrm{mmHg})$ in the Bactron anaerobic incubator.

Assaying the effects of hypoxia on cytotrophoblast protein synthesis, glucose metabolism, and hormone secretion. Cytotrophoblasts $\left(10^{6}\right)$ were plated in 16-mm Matrigel-coated tissue culture wells (6). Routinely, the cells were maintained in either 2 or $20 \%$ oxygen. When indicated, the cells were also incubated in an $8 \%$ oxygen atmosphere.

Incorporation of $\left[{ }^{35} \mathrm{~S}\right] \mathrm{methionine} / \mathrm{cysteine}$ into cellular and secreted proteins was quantified as follows. Unless otherwise indicated, all reagents were obtained from Sigma Chemical Co., St. Louis, MO. Cytotrophoblasts were cultured for $12 \mathrm{~h}$ on Matrigel substrates. Then they were washed three times with methionine-free DME, after which they were cultured for an additional $12 \mathrm{~h}$ in $1 \mathrm{ml}$ of the same medium containing $100 \mu \mathrm{Ci}$ of a mixture of $\left[{ }^{35} \mathrm{~S}\right]$ methionine and ${ }^{[35}$ S $]$ cysteine $(1175 \mathrm{Ci} / \mathrm{mmol}$; New England Nuclear; Wilmington, $\mathrm{DE})$. At the end of the labeling period the cells were washed twice with $1 \mathrm{ml}$ fresh DME, then detached from the Matrigel and dispersed 
by treatment with Dispase $(0.5 \mathrm{ml} /$ well; Collaborative Biomedical Products). After $2 \mathrm{~h}$ at $37^{\circ} \mathrm{C}$ the enzymatic activity was stopped by adding $1 \mathrm{ml}$ of $5 \mathrm{mM}$ EDTA. Cytotrophoblasts were washed three times by centrifugation $(800 \mathrm{~g}, 5 \mathrm{~min})$, resuspended in $1 \mathrm{ml} \mathrm{Ca}^{2+}$, $\mathrm{Mg}^{2+}$-free PBS, and the number of cells was counted in a hemocytometer. Then the cytotrophoblasts were again pelleted by centrifugation and resuspended $\left(10^{6}\right.$ cells $\left./ 100 \mu \mathrm{l}\right)$ in lysis buffer (PBS containing $1 \%$ Triton X-100, $1 \mathrm{mM}$ PMSF, $5 \mu \mathrm{g} / \mathrm{ml}$ DNase I, $5 \mu \mathrm{g} / \mathrm{ml}$ RNase A, $5 \mathrm{mM} \mathrm{MgCl} 2,5 \mu \mathrm{g} / \mathrm{ml}$ leupeptin, $20 \mu \mathrm{g} / \mathrm{ml}$ aprotinin, and $5 \mu \mathrm{g} / \mathrm{ml}$ soybean trypsin inhibitor). Aliquots $(3 \times 100 \mu \mathrm{l})$ of cell lysate were precipitated with $100 \mu \mathrm{l}$ of ice-cold $20 \%$ TCA for $20 \mathrm{~min}$ at $4^{\circ} \mathrm{C}$. The resulting suspensions were collected by vacuum filtration onto glass microfiber disks. The disks were washed twice with $5 \mathrm{ml}$ ice-cold $10 \%$ TCA and once with $5 \mathrm{ml} 100 \%$ ethanol, then transferred to vials containing scintillation cocktail (Ultima-gold; Packard Instruments, Meriden, CT), and radioactivity was determined using a LS1701 counter (Beckman Instruments Inc., Brea, CA). The conditioned medium $(100 \mu \mathrm{l})$ was frozen until it was subjected to TCA precipitation in parallel with the cell pellet. Cells and medium from three replicate cultures established from each of five separate cell isolation procedures were analyzed.

The amount of glucose and lactate in conditioned medium from cells cultured for $72 \mathrm{~h}$ was determined enzymatically using commercial glucose oxidase and lactate dehydrogenase assay kits (Sigma). Values were calculated as the difference between glucose and lactate in conditioned medium and fresh culture medium. Culture medium from three replicate cultures established from each of 10 separate cell isolation procedures was analyzed.

Cytotrophoblast secretion of human chorionic gonadotropin (hCG) and human placental lactogen (hPL) during the first $72 \mathrm{~h}$ of culture was measured by competition ELISA. Wells of ELISA plates (Dynatech Laboratories Inc., Chantilly, VA) were coated with antigen by adding $100 \mu \mathrm{l}$ of a stock solution of either hPL (bicarbonate buffer, $\mathrm{pH} 9.5)$ or $\beta$ hCG $(1 \mu \mathrm{g} / \mathrm{ml}$ PBS $)$ and incubating overnight at $4^{\circ} \mathrm{C}$. Both hormones were obtained from Sigma. Routinely, $75 \mu \mathrm{l}$ of medium was transferred to cluster tubes, and then an equal volume of antibodies diluted in PBS containing $0.05 \%$ Tween- 20 and $1 \%$ nonfat dried milk (PBST) was added. The mouse monoclonal anti-hPL antibody (INN hPL5, Harlan Bioproducts for Science, Indianapolis, IN) was used at a dilution of 1:13,000 ( $\mathrm{vol} / \mathrm{vol})$ and the rabbit polyclonal anti- $\beta$ hCG antibody (Hycor Biomedical Inc., Irvine, CA) at a dilution of $1: 10,000(\mathrm{vol} / \mathrm{vol})$. Then the samples were incubated at $37^{\circ} \mathrm{C}$ for $1 \mathrm{~h}$. Just before the start of the assay, the ELISA plates were blocked by incubating for at least $45 \mathrm{~min}$ in $100 \mu \mathrm{l}$ PBST. Then the wells were rinsed once with PBST and emptied, after which $100 \mu$ of the medium-antibody mixture was transferred to each well. The samples were incubated for $2 \mathrm{~h}$ and washed five times with PBST. Then $100 \mu \mathrm{l}$ of a solution of peroxidase-conjugated secondary antibody (goat anti-mouse for hPL, 1:1000 [vol/vol] in PBST; goat anti-rabbit for $\beta \mathrm{hCG}, 1: 3000$ [vol/vol] in PBST; both obtained from Jackson ImmunoResearch Laboratories, Inc., West Grove, PA) was added and the samples were incubated for an additional $1 \mathrm{~h}$. After extensive washing with PBST, $100 \mu \mathrm{l}$ of a $5 \mathrm{mg} / \mathrm{ml}$ solution of $o$-phenylenediamine substrate in $85 \mathrm{mM}$ citrate buffer was added to each well. The samples were incubated in the dark for $10 \mathrm{~min}$ to allow color development. The reaction was stopped by adding $50 \mu \mathrm{l} 4 \mathrm{~N} \mathrm{H}_{2} \mathrm{SO}_{4}$ to each well. $\mathrm{A}_{490}$ was determined, and data were generated by four-parameter curve analysis using a reference preparation of either hPL (World Health Organization [WHO], NIBSC 75/545) or $\beta$ hCG (WHO, 1st IRP 75/551). The standard curves covered six dilutions; 3-100 ng for $\mathrm{hPL}$ and 5-160 mIU/ml for $\beta$ hCG. Culture medium from three replicate cultures established from each of five separate cell isolation procedures was analyzed.

Assaying the effects of hypoxia on cytotrophoblast DNA synthesis. DNA synthesis was assayed in two ways. First, cytotrophoblasts $\left(10^{6}\right)$ from $10-12 \mathrm{wk}$ placentas were plated in 16-mm Matrigel-coated tissue culture wells (6) in either a 2 or a $20 \%$ oxygen atmosphere. After $48 \mathrm{~h}$, medium containing $5 \mu \mathrm{Ci} / \mathrm{ml}\left[{ }^{3} \mathrm{H}\right]$ thymidine $(44 \mathrm{Ci} / \mathrm{mM}$; Am- ersham Corp., Arlington Heights, IL) was added. After $72 \mathrm{~h}$ the medium was aspirated. The cells were washed three times with $2 \mathrm{ml}$ PBS containing unlabeled thymidine $(5 \mu \mathrm{g} / \mathrm{ml})$, treated with Dispase, and lysed. Radioactivity was measured after TCA precipitation as described above. Cells and medium from three replicate cultures prepared from each of three separate isolation procedures were analyzed.

Second, cytotrophoblasts $\left(2.5 \times 10^{5}\right)$ isolated from two separate pools of $10-12$ wk gestation placentas were cultured on Matrigelcoated filters for $48 \mathrm{~h}$ in either a 2 , an 8 , or a $20 \%$ oxygen environment. The culture medium was aspirated, and medium containing $1 \mu \mathrm{M}$ of the thymidine analogue, 5-bromo-2'-deoxyuridine (BrdU; Sigma Chemical Co.), was added. After $24 \mathrm{~h}$ the experiment was terminated. The filters were washed $2 \times$ for $20 \mathrm{~min}$ in PBS, fixed in $3 \%$ paraformaldehyde for $1 \mathrm{~h}$ at $4^{\circ} \mathrm{C}$, washed again in PBS (3×,10 min), and permeabilized in cold methanol for $10 \mathrm{~min}$. After rinsing in PBS $(3 \times, 20 \mathrm{~min})$ they were incubated with a fluorescein-labeled anti-BrdU antibody according to the manufacturer's directions (Boehringer Mannheim Biochemicals). To verify that cells were cytotrophoblasts, the filters were rinsed again in PBS $(3 \times, 10 \mathrm{~min})$, incubated overnight with a rat anticytokeratin $\mathrm{mAb}(7 \mathrm{D} 3 ; 3)$, and immunoreactivity was detected using a goat anti-rat $\mathrm{IgG} \mathrm{mAb}$ conjugated to Texas red (Jackson ImmunoResearch Laboratories Inc.). Filters were dissected from the inserts with a scalpel blade and mounted on polylysinecoated slides in a drop of mounting medium such that the top of the filter faced upward. The percentage of cytokeratin-positive cells that incorporated $\mathrm{BrdU}$ was determined by examining 500 cells from five randomly selected areas of each filter. Two filters were analyzed from each experimental group.

Invasion assays. Two assays were used. First, cytotrophoblasts were cultured with decidual explants. Briefly, portions of the decidua parietalis, which does not contain cytotrophoblasts before culture, were obtained at the time of pregnancy termination (10-12 wk). The tissue was washed three times in ice-cold PBS and cut into 2- $\mathrm{mm}^{3}$ pieces. After washing another three times, five decidual pieces in 500 $\mu \mathrm{l}$ medium (DME $/ 2 \%$ Nutridoma) were plated on each of several Millicel inserts (12-mm diameter; Millipore Corp., Bedford, MA) coated with $200 \mu \mathrm{l}$ Matrigel. The inserts were transferred to $16-\mathrm{mm}$ culture dishes containing $600 \mu \mathrm{l}$ medium and incubated for $6 \mathrm{~h}$, the amount of time required for the explants to attach to the ECM substrate. Then the medium was aspirated from the upper chamber, and $5 \times 10^{5}$ cytotrophoblasts in $500 \mu \mathrm{l}$ of medium was added. The cultures were maintained for up to $4 \mathrm{~d}$, and medium was changed daily. At various time points $(24,48,72$, and $96 \mathrm{~h})$ the samples were fixed in $3 \%$ paraformaldehyde for $40 \mathrm{~min}$, washed three times in $\mathrm{PBS}\left(4^{\circ} \mathrm{C}, 10\right.$ min), infiltrated with sucrose, embedded in OCT (Miles Scientific, Naperville, IL), and frozen in liquid nitrogen. Sections $(6 \mu \mathrm{m})$ were cut using a cryostat (Slee International Inc., Tiverton, RI) and collected on poly-L-lysine-coated microscope slides. The sections were incubated for $1 \mathrm{~h}$ with primary anticytokeratin antibody (7D3), which reacts with cytotrophoblasts but not other villous components, diluted 1:100 ( $\mathrm{vol} / \mathrm{vol})$ in PBS. Then they were rinsed in PBS (three times for $10 \mathrm{~min}$ ) and incubated for $30 \mathrm{~min}$ with rhodamine-conjugated goat anti-rat IgG (Jackson ImmunoResearch Laboratories, Inc.) diluted 1:100 (vol/vol) in PBS. The samples were examined using a confocal microscope (600; Bio-Rad Laboratories, Richmond, CA). Three explants from each of five separate isolation procedures were analyzed.

Second, to quantify invasion, cytotrophoblasts $\left(2 \times 10^{5}\right)$ were cultured in Matrigel-coated Transwell inserts (6.5 mm; Costar Corp.) containing polycarbonate filters with $8-\mu \mathrm{m}$ pores (6) in either a 2 or a $20 \%$ oxygen atmosphere. After $72 \mathrm{~h}$ the cultures were rinsed in PBS, fixed, and stained with anticytokeratin antibodies as described above. To assay invasion the filters were dissected from the inserts with a scalpel blade and mounted on poly-L-lysine-coated slides in a drop of mounting medium such that the underside of the filters faced upward. Serial optical sections $(1 \mu \mathrm{m})$ that included the upper (Matrigelcoated) and lower filter surfaces, as well as the pores that connected 
them, were obtained by using confocal microscopy. The number of cytokeratin-positive cell processes that penetrated the Matrigel and appeared on the underside of the filters was counted. Three filters were used for each experimental group. The total number of filters analyzed for cells in each gestational age group is summarized in Fig. 4. In additional experiments cytotrophoblasts were cultured in a 2, an 8 , and a $20 \%$ oxygen atmosphere. The total number of filters analyzed in each experimental group is summarized in Fig. 5.

Statistical analyses. Statistical significance of the data was tested using Student's paired $t$ test. Results were considered significant at the 0.05 level.

Immunofluorescence localization. Tissue samples of the normal and preeclamptic placental bed were obtained as previously described $(3,15)$. The methods we used to fix the samples and to detect cytokeratin-positive cytotrophoblasts have also been described $(3,15)$.

Integrin and ECM expression by cultured cytotrophoblasts was analyzed by confocal microscopy. The cells were fixed and processed as described above. In all cases the cells were double stained with either antiintegrin $(\alpha 5, \alpha 1, \beta 1)$ or anti-ECM (collagen IV and fibronectin) antibodies and antibodies that detect cytokeratin as described previously $(3,5,9)$. The samples were analyzed by using dual channel fluorescence imaging.

\section{Results}

Many cytotrophoblast cellular processes were not affected by hypoxia. Initial experiments suggested, based on the cell's morphology, that culturing cytotrophoblasts for $72 \mathrm{~h}$ in $2 \% \mathrm{O}_{2}$ (comparable to the oxygen concentration at the intervillous space at 8-10 wk gestation) had no obvious negative effects. To confirm this impression we assayed the cells' ability to exclude Trypan blue. In a $20 \% \mathrm{O}_{2}$ atmosphere $93.5 \pm 3.8 \%$ of all the cells (attached and unattached; see below) excluded this dye, as compared with $93.5 \pm 6.4 \%$ of the cells cultured in a $2 \%$ $\mathrm{O}_{2}$ atmosphere.

We also assayed several parameters that reflected both generalized and specialized aspects of the cells' functions (Table I). As to the general state of the cells, those cultured in 20 or $2 \%$ oxygen incorporated nearly identical amounts of $\left[{ }^{35} \mathrm{~S}\right]$ methionine/cysteine into proteins. Likewise, they secreted comparable amounts of TCA-precipitable, ${ }^{35}$ S-labeled proteins into the culture medium. Recent experiments in which we analyzed, by using 2-D gel analyses, the effects of hypoxia

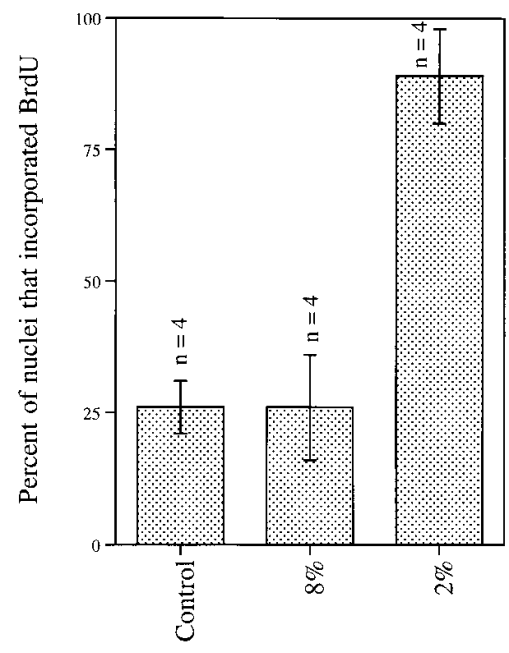

Figure 1. Culturing cytotrophoblasts in a $2 \%$ oxygen atmosphere produced a threefold increase in their incorporation of BrdU compared with control cells cultured in $2 \%$ oxygen $(P<0.01)$. Cells were isolated from two separate pools of $10-12 \mathrm{wk}$ gestation placentas. The percentage of cytokeratin-positive cells that incorporated BrdU was determined by examining 500 cells from five randomly selected areas of each filter. Two filters were established from two different isolation procedures. Error bars show $\mathrm{SD}$.

on cytotrophoblast production of individual ${ }^{14} \mathrm{C}$-labeled proteins substantiated these results (data not shown). Of the $\sim 200$ spots seen on the gels, the intensity of only 10 changed ( 7 upregulated, 3 downregulated [Falk, R., and S. J. Fisher, manuscript in preparation]). Similarly, there were no significant differences in either glucose uptake or lactate production by cells maintained under the two culture conditions. As to specialized cytotrophoblast functions, we assayed the effects of hypoxia on hormone release. Secretion of neither human chorionic gonadotropin nor human placental lactogen changed in response to lowering oxygen tension.

Hypoxia stimulates cytotrophoblast incorporation of $\left[{ }^{3} H\right]$ thymidine and $B r d U$. In many cells, differentiation is coupled with exit from the cell cycle. Cytotrophoblast stem cells and those that are in the initial stages of differentiation in vivo react with antibodies that recognize Ki67 and proliferating cell nuclear antigen, antigens expressed by dividing cells $(42,43)$,

Table I. The Effects of Hypoxia on Cytotrophoblast Protein Synthesis, Glucose Metabolism, Hormone Secretion, and $\left[{ }^{3} H\right]$ thymidine Incorporation (values are means $\pm S E$ )

\begin{tabular}{|c|c|c|}
\hline \multirow[b]{2}{*}{ Parameter assayed } & \multicolumn{2}{|c|}{ Oxygen content of medium } \\
\hline & $20 \%$ & $2 \%$ \\
\hline \multicolumn{3}{|l|}{$1 \times 10^{6}$ cells } \\
\hline \multicolumn{3}{|c|}{${ }^{35} \mathrm{~S}$-amino acid incorporation into TCA-precipitable protein $(\mathrm{cpm}) *$} \\
\hline Medium $(n=15)$ & $0.3 \times 10^{6} \pm 0.4 \times 10^{5}$ & $0.3 \times 10^{6} \pm 0.3 \times 10^{5}$ \\
\hline Cell-associated $(n=15)$ & $1.6 \times 10^{6} \pm 0.3 \times 10^{5}$ & $1.4 \times 10^{6} \pm 0.2 \times 10^{5}$ \\
\hline Glucose consumption $(\mu \mathrm{g})^{\ddagger}(n=30)$ & $2.6 \pm 0.4$ & $3.1 \pm 0.5$ \\
\hline Lactate production $(\mathrm{mg})^{\ddagger}(n=30)$ & $5.2 \pm 7$ & $4.8 \pm 9$ \\
\hline hCG secretion $(\mathrm{mIU})^{\ddagger}(n=15)$ & $60 \pm 4.8$ & $58 \pm 5.3$ \\
\hline hPL secretion $(n g)^{\ddagger}(n=15)$ & $638 \pm 172$ & $585 \pm 168$ \\
\hline \multicolumn{2}{|l|}{$\left[{ }^{3} \mathrm{H}\right]$ thymidine incorporation $(\mathrm{cpm})^{\S}(n=9)$} & $18,689 \pm 1,479 \|$ \\
\hline
\end{tabular}

* Samples were collected after cytotrophoblasts were cultured for $12 \mathrm{~h} .{ }^{\ddagger}$ Conditioned medium was collected after cytotrophoblasts were cultured for $72 \mathrm{~h} .{ }^{8}$ Cytotrophoblasts were incubated with $\left[{ }^{3} \mathrm{H}\right]$ thymidine-containing media between 48 and $72 \mathrm{~h}$ of culture. ${ }^{\|}<0.05$. 

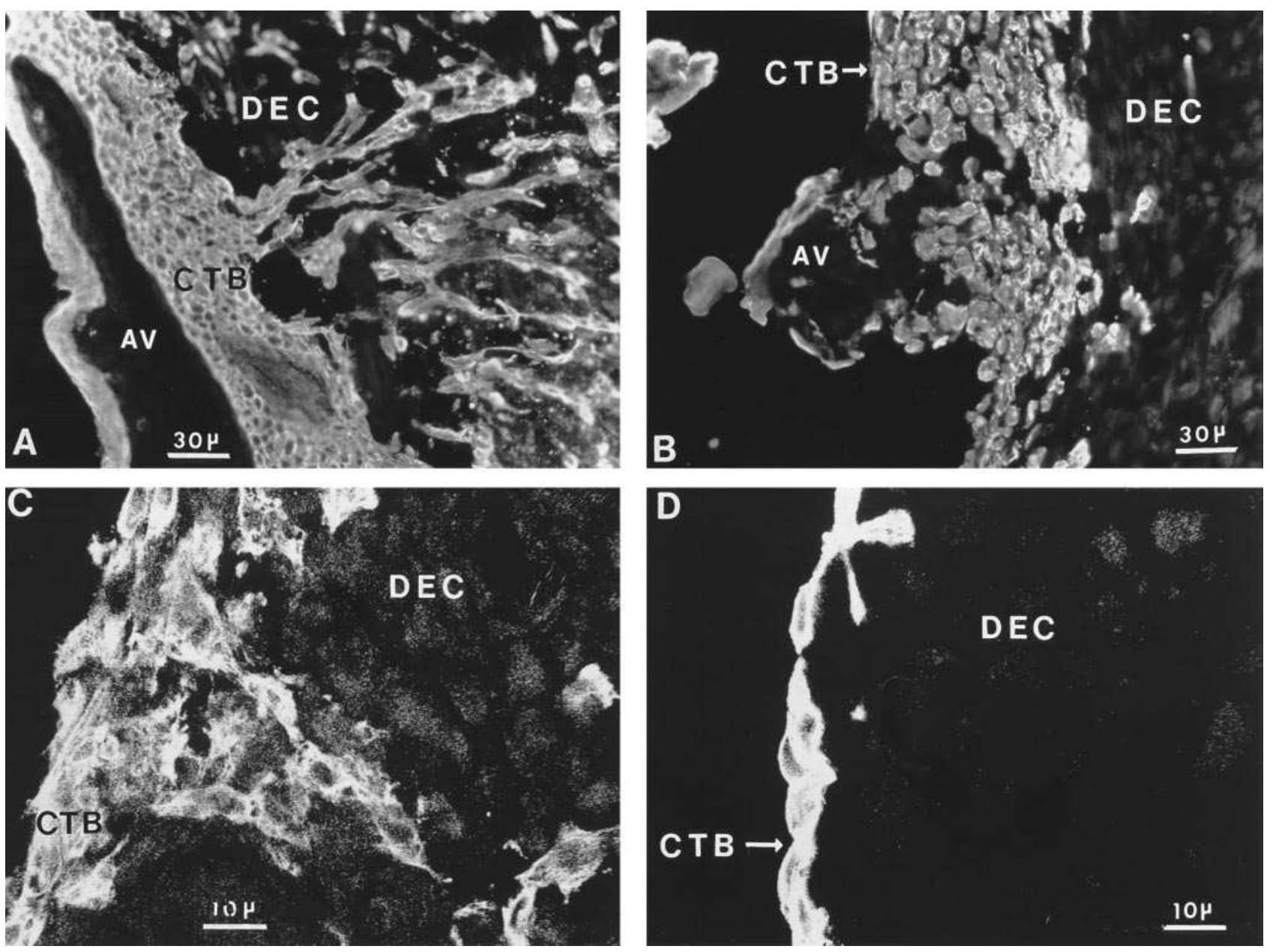

Figure 2. Comparing human cytotrophoblast invasion in normal $(A)$ and preeclamptic $(B)$ pregnancies in vivo with cytotrophoblast-decidual interactions in cultured explants maintained in $20 \%(C)$ or $2 \%(D)$ oxygen. Frozen sections of the maternal-fetal interface (36 wk) were stained with anticytokeratin antibodies and fluorescein-conjugated secondary antibodies. In normal pregnancy $(A)$, cytokeratin-positive cytotrophoblasts $(C T B)$ connected anchoring villi $(A V)$ to the uterus and were found throughout the decidua $(D E C)$. In preeclampsia $(B)$, cytotrophoblast invasion was limited to the superficial portion of the decidua. We compared these interactions with those occurring when purified first trimester human cytotrophoblasts invaded decidual explants in vitro. After $72 \mathrm{~h}$ the cultures were fixed, stained with anticytokeratin antibodies and fluorescein-conjugated secondary antibodies, and then viewed by confocal microscopy. In a $20 \%$ oxygen atmosphere $(C)$, cytokeratin-positive cytotrophoblasts attached to and invaded the decidua. In a $\%$ oxygen atmosphere $(D)$, cytotrophoblasts attached to the decidual explants, but invasion was significantly reduced.

but those which are fully differentiated do not. To begin to understand whether hypoxia affects cytotrophoblast differentiation, we determined whether lowering the oxygen tension changes the fraction of cytotrophoblasts that enter $\mathrm{S}$ phase. We found that cells cultured in $2 \%$ oxygen incorporated twice the amount of $\left[{ }^{3} \mathrm{H}\right]$ thymidine as did those cultured in a $20 \%$ oxygen atmosphere (Table I).

Similarly, BrdU incorporation increased approximately threefold when 10-12 wk human cytotrophoblasts were cultured in a $2 \%$, as compared with a $20 \%$, oxygen environment (Fig. 1). We also studied BrdU incorporation by cytotrophoblasts that were incubated in an $8 \%$ oxygen atmosphere, i.e., comparable to the oxygen content measured in the endometrium during the first trimester and in the intervillous space after 12 wk of pregnancy (39). Incorporation was virtually identical to that observed under standard tissue culture conditions $\left(20 \% \mathrm{O}_{2}\right)$.

Hypoxia inhibits cytotrophoblast invasion. Next, we deter- mined whether hypoxia inhibits cytotrophoblast differentiation along the invasive pathway. We assayed two endpoints: invasive behavior (described in this section) and integrin, stage-specific antigen expression (described in the next section). In vivo, differentiation/invasion of cytotrophoblast stem cells results in penetration of the uterus and its blood vessels (3). In vitro the cells invade decidual explants or isolated ECMs $(5,6)$. Here we used both of these invasion models. In $20 \%$ oxygen, interactions between cytotrophoblasts and decidual explants appeared similar to those of cytotrophoblasts invading the decidua in vivo (compare Figs. $2, A$ and $C$ ); elongated, cytokeratin-positive cells invaded deeply into the uterine tissue. In $2 \%$ oxygen, there was no change in the number of cytotrophoblasts that attached to the explants $(87.6 \pm 12.4 \%$ in $20 \% \mathrm{O}_{2}$ vs. $88.5 \pm 9.9 \%$ in $2 \% \mathrm{O}_{2}$ ). But most of these cells aggregated on the tissue surface, and invasion was markedly reduced (Fig. $2 \mathrm{D}$ ). In this case interactions between the fetal and maternal cells were morphologically similar to those ob- 

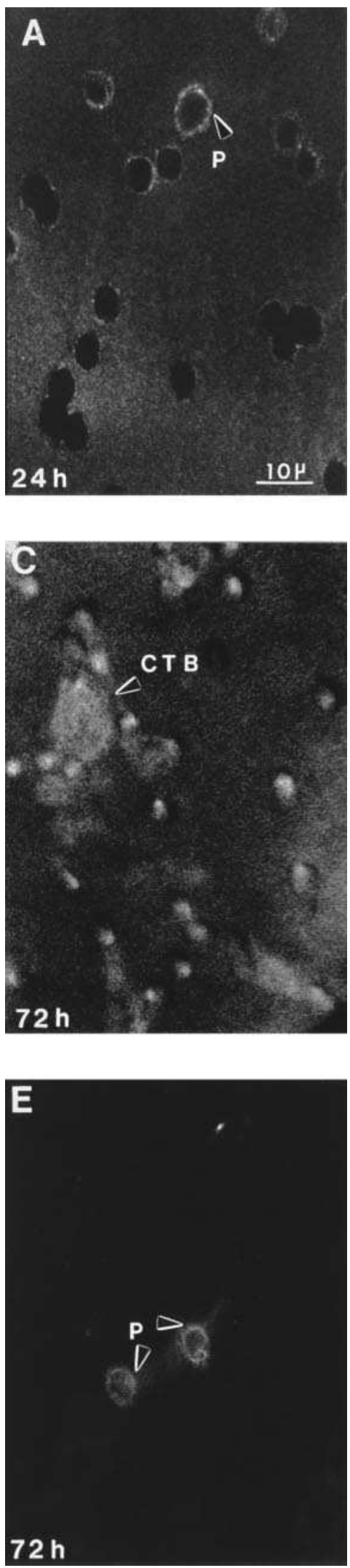
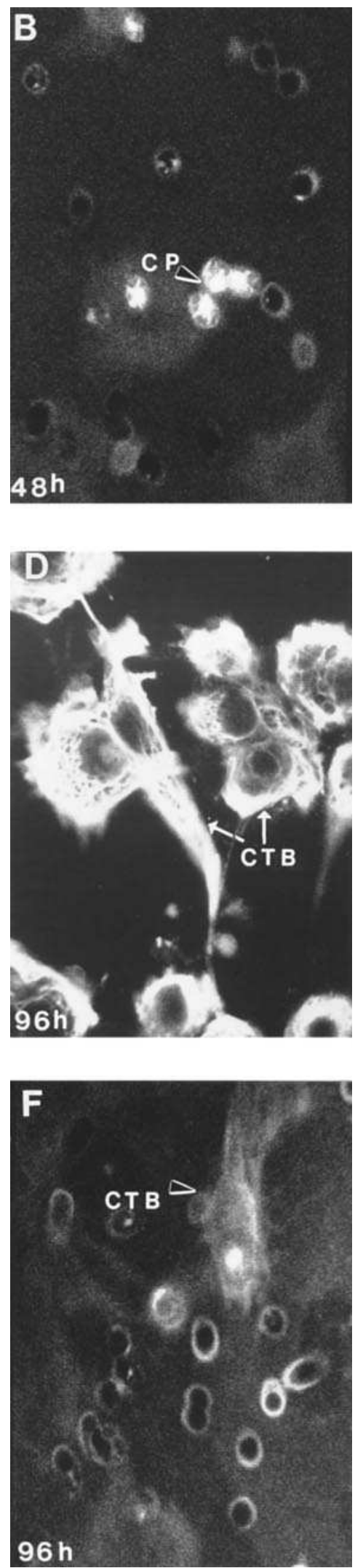

Figure 3. Reducing oxygen tension inhibited early gestation human cytotrophoblast invasion. Cytotrophoblasts isolated from pools of 10-12 wk placentas were cultured on Matrigel-coated $(100 \pm 6 \mu \mathrm{m})$ Transwell filters. After $24,48,72$, or $96 \mathrm{~h}$ the cultures were fixed and stained with anticytokeratin antibodies. The filters were removed from the inserts, inverted onto microscope slides and examined using a confocal microscope. We viewed $1-\mu \mathrm{m}$ sections that were parallel to the membrane. The area we examined $(50 \mu \mathrm{m}$ total $)$ included the underside as well as the upper surface of the filter and its Matrigel coating. Thus, the images appeared black unless fluorescently labeled (cytokeratin-positive) cells invaded to within $50 \mu \mathrm{m}$ of the filter. $(A-D)$ When the cultures were maintained in $20 \%$ oxygen, cytotrophoblasts $(C T B)$ penetrated the Matrigel and emerged on the undersurface of the filter within $96 \mathrm{~h}$ of plating. By $24 \mathrm{~h}(A)$ fluorescent-labeled cells had started to invade the Matrigel. As a result, the emitted fluorescence was sufficient to make the filter surface appear light and the pores $(P)$ appear black. Cytokeratinpositive cell processes $(C P)$ were first seen in the pores at $48 \mathrm{~h}(B)$. By $72 \mathrm{~h}(C)$ many cells appeared near the original upper surface of the filter (CTB; arrow heads), and most of the filter pores contained cell processes. Between $72(C)$ and $96 \mathrm{~h}(D)$ invasion proceeded rapidly, and entire cells $(C T B$; arrows) emerged on the filter underside. $(E$ and $F$ ) When the cultures were maintained in 2\% oxygen, invasion was significantly retarded. After $72 \mathrm{~h}(E)$ the filter surface still appeared black, indicating that cytokeratin-positive cells were not within the $50 \mu \mathrm{m}$ area that was imaged. Cytotrophoblasts near the upper surface of the filter and cell processes in some of the pores were first visible at $96 \mathrm{~h}(F)$. 


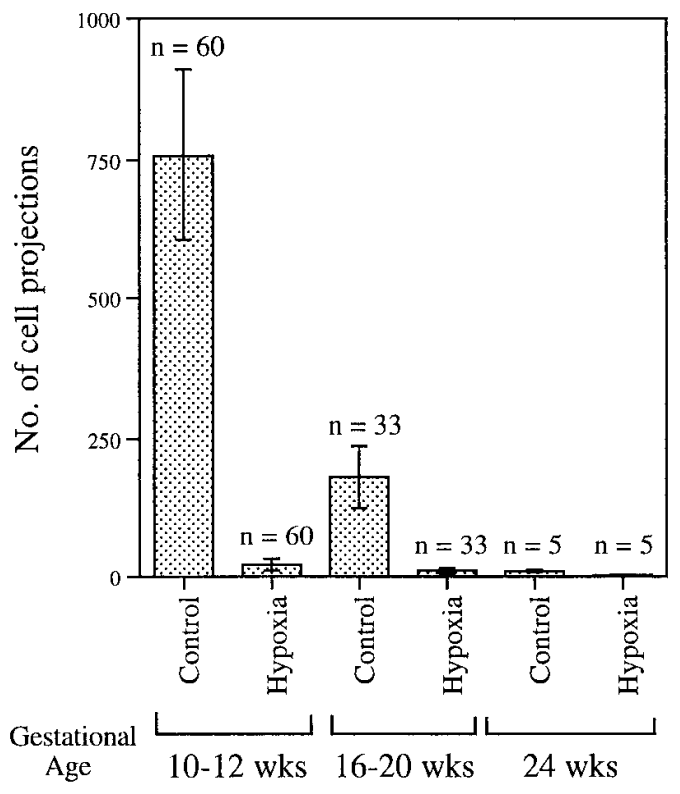

Figure 4. Quantifying the effects of hypoxia on early gestation human cytotrophoblast invasion. Cytotrophoblasts isolated from pools of $10-12,16-20$, or 24 wk placentas were cultured for $72 \mathrm{~h}$ on Matrigel-coated Transwell filters. Invasion was quantified by counting the number of cytokeratin-positive cell processes that penetrated the filter pores. As previously described, the invasiveness of control cells cultured under standard conditions ( $20 \%$ oxygen) decreased with advancing gestational age $(6,8)$. Culturing cytotrophoblasts isolated from either 10-12 or 16-20 wk placentas under hypoxic conditions ( $2 \%$ oxygen) significantly inhibited their invasiveness $(P<0.001$ for $10-12$ wk cells; $P<0.001$ for $16-20$ wk cells). $n$, number of filters. Three replicate filters were established from each isolation procedure, except that five filters from a single $24 \mathrm{wk}$ placenta were analyzed. Error bars show SD.

served in tissue sections of the maternal-fetal interface in pregnancies complicated by preeclampsia (compare Fig. 2, $B$ and $D)$; the cells attached to the uterus, but invasion was shallow.

The other model we used allowed us to quantify differences in cytotrophoblast invasiveness and to determine whether hypoxia-induced changes required coculture with decidual explants. Purified 10-12 wk cytotrophoblasts were plated on the tops of Matrigel-coated Transwell filters (5, 6, 8, 9). After 24-96 h the filters were dissected from the inserts and mounted on slides such that their undersides faced upward. We used confocal microscopy to image the ECM, both sides of the filter and the pores that connected them. This showed that

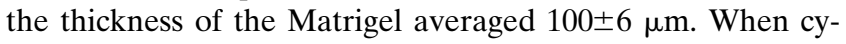
totrophoblasts were plated in a $20 \% \mathrm{O}_{2}$ atmosphere, we observed the following progression. After the first $24 \mathrm{~h}$ of culture, cells had not penetrated the Matrigel to a sufficient depth to be visible in the area adjacent to the filter (Fig. $3 A$ ). After $48 \mathrm{~h}$, a few cells had invaded the Matrigel, and occasionally their processes traversed the pores (Fig. 3 B). However, by $72 \mathrm{~h}$ a large number of cells were in direct contact with the filter, and many pores contained processes (Fig. $3 \mathrm{C}$ ). After this stage invasion proceeded rapidly; at the end of the culture period (96 h) numerous cells had reached the underside of the filter (Fig. $3 \mathrm{D}$ ). In contrast, cytotrophoblasts that were cultured in $2 \%$ oxygen were much less invasive. By $72 \mathrm{~h}$ cells were only occasionally visible near the upper surface of the filter (Fig. $3 E$ ). Even by

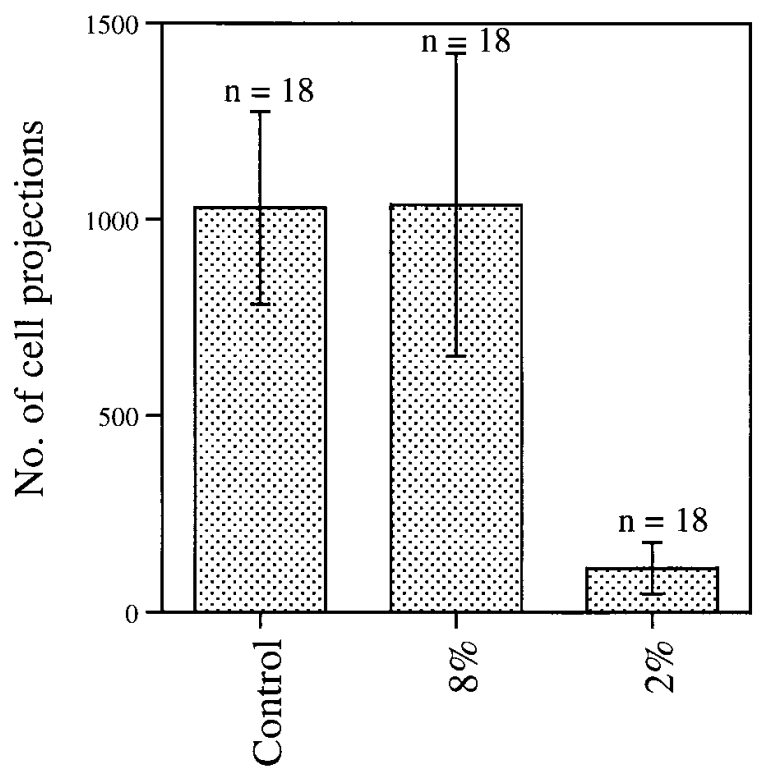

Figure 5. Cytotrophoblasts cultured in a 20 and an $8 \%$ oxygen atmosphere were similarly invasive. Cytotrophoblasts isolated from 10-12 wk placentas were cultured for $3 \mathrm{~d}$ on Matrigel-coated Transwell filters and invasion was quantified as described in Fig. 4. The cells were maintained under standard tissue culture conditions $\left(20 \% \mathrm{O}_{2}\right.$; Control), or in an atmosphere with an oxygen content comparable to that of the endometrium $(8 \%)$, or under hypoxic conditions $\left(2 \% \mathrm{O}_{2}\right)$. The invasiveness of cells cultured in 20 and $8 \% \mathrm{O}_{2}$ was similar and significantly $(P<0.01)$ greater than that of cells maintained in a $2 \% \mathrm{O}_{2}$ atmosphere. $n$, number of filters. Six replicate filters were analyzed from three different isolation procedures. Error bars show SD.

$96 \mathrm{~h}$, few processes had penetrated the pores or reached the filter underside (Fig. $3 F$ ).

Next, we quantified the inhibitory effects of hypoxia on cytotrophoblast invasion by counting the number of cytokeratinpositive cell processes that extended through the filter after $72 \mathrm{~h}$, the time when numerous cell processes had traversed the pores, but passive migration through previously formed tracks had not yet begun. We focused on gestational ages 8-24 wk because our previous studies showed that cytotrophoblast invasiveness peaks early in the first trimester and is greatly reduced by mid-gestation $(6,8)$. The results (Fig. 4) showed that there was a $90 \%$ reduction in invasion when cytotrophoblasts isolated from $10-12 \mathrm{wk}$ placentas were plated in $2 \%$ as compared with $20 \%$ oxygen. Similar results were obtained when we assayed the invasive capacity of cells isolated from 16-20 wk placentas cultured in the two conditions. By $24 \mathrm{wk}$, little invasion was evident in either the control or experimental cultures. These results suggest that low oxygen tension inhibits invasion by its direct effects on early gestation cytotrophoblasts, rather than by an indirect mechanism mediated by the decidua.

We then assayed the effects on cytotrophoblast invasion of maintaining cells isolated from 10-12 wk placentas in an $8 \%$ oxygen atmosphere, comparable to that encountered by cells in the endometrium during the first trimester and in the intervillous space after 12 wk of gestation (39). As shown in Fig. 5, the number of cell projections that reached the underside of the filter was nearly identical to that observed when the cultures were maintained in a $20 \%$ oxygen atmosphere.

To determine whether the negative effects of hypoxia on 


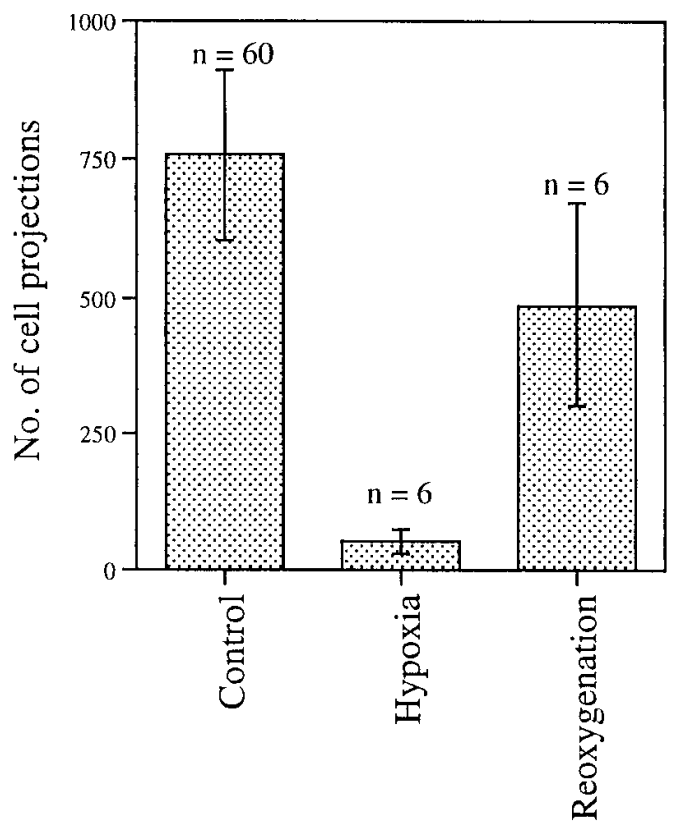

Figure 6. Reoxygenation reversed the negative effects of hypoxia on first trimester human cytotrophoblast invasion. Cytotrophoblasts isolated from 10-12 wk placentas were cultured for $6 \mathrm{~d}$ on Matrigelcoated Transwell filters and invasion was quantified as described in Fig. 4 . The cells were either maintained in a $2 \%$ oxygen atmosphere for the entire period (Hypoxia) or transferred after $3 \mathrm{~d}$ to a standard tissue culture incubator ( $20 \%$ oxygen; Reoxygenation). In the latter case, invasion reached a level that was not significantly different from that of cells cultured for $3 \mathrm{~d}$ in a $20 \%$ oxygen environment (Control). $n$, number of filters. Three replicate filters were established from each isolation procedure. Error bars show SD.

cytotrophoblast (10-12 wk) invasion could be reversed, cells were either cultured for $6 \mathrm{~d}$ in $2 \%$ oxygen or switched after $3 \mathrm{~d}$ to a $20 \%$ oxygen atmosphere, where they were maintained for an additional $3 \mathrm{~d}$. The results are shown in Fig. 6. As expected, cells that were continuously cultured under hypoxic conditions showed little ability to invade the ECM. In contrast, the invasiveness of cytotrophoblasts that were switched from 2 to $20 \%$ oxygen approached that of cells cultured under standard conditions for $3 \mathrm{~d}$. The latter data (replicated from Fig. 4) were used for comparison purposes because nearly all of the early gestation cells that were cultured in a $20 \%$ oxygen atmosphere for $6 \mathrm{~d}$ had penetrated the pores and reaggregated on the bottoms of the filters. Thus, the short-term effects of hypoxia on cytotrophoblast invasion are reversible, suggesting that under some circumstances cytotrophoblasts may be relatively resistant to reoxygenation injury.

Hypoxia inhibits cytotrophoblast $\alpha 1 / \beta 1$ integrin expression. The third endpoint we assayed was the cells' expression of integrin cell-ECM receptors which are stage-specific markers for transitions in cytotrophoblast differentiation, as well as important regulators of the invasion process. Plating 10-12 wk gestation cytotrophoblast stem cells on Matrigel supports their differentiation along the invasive pathway, as assayed by the cells' ability to alter their integrin repertoire (9). Here, we used this culture system to determine whether hypoxia alters the normal pattern of cytotrophoblast integrin switching. As we showed previously (9), cytotrophoblast stem cells maintained in $20 \% \mathrm{O}_{2}$ rapidly upregulated their expression of integrins $\alpha 5$
(Fig. $7 A$ ) and $\beta 1$, as well as ECM constituents (collagen IV and $\mathrm{A}^{+} \mathrm{B}^{+}$fibronectin) (data not shown). In vivo these molecules are first expressed just after the cells leave their basement membrane (3), i.e., during the initial stages of differentiation. Under standard culture conditions (20\% oxygen), cytotrophoblasts also upregulated integrin $\alpha 1$ expression (Fig. $7 \mathrm{C}$ ). In vivo this occurs at a later point in the differentiation process, i.e., as the cells invade the uterus (3). The same results were obtained when the cells were cultured in an $8 \%$ oxygen atmosphere. Cytotrophoblasts cultured in $2 \% \mathrm{O}_{2}$ completed the initial stages of this differentiation program. They upregulated expression of $\alpha 5$ (Fig. 7 B) and $\beta 1$ integrin subunits, as well as collagen IV and fibronectin production (data not shown). However, the majority of cytokeratin-positive cells failed to express $\alpha 1 \beta 1$ (Fig. $7 E$ ), suggesting that they can initiate, but not complete, the normal integrin switching program.

\section{Discussion}

The results of these experiments, taken together, suggest that oxygen tension is one factor that regulates human cytotrophoblast differentiation along the invasive pathway. In a hypoxic environment, the cells carry out only the initial stages of their normal differentiation program. They upregulate DNA synthesis and express integrins and ECM molecules (e.g., $\alpha 5 / \beta 1$ and $\mathrm{A}^{+} \mathrm{B}^{+}$fibronectin) in a pattern characteristic of cytotrophoblasts in the early stages of differentiation along the invasive pathway in vivo $(3,9)$. However, the latter stage of the differentiation process, in which cytotrophoblasts upregulate the expression of integrin $\alpha 1 / \beta 1$, is inhibited in a manner that is similar to the situation we have observed in preeclampsia (15, 16). Comparing the invasiveness of cytotrophoblasts cultured in 2 and $20 \%$ oxygen suggests that the changes in stage-specific antigen expression we observed had functional consequences: culturing cytotrophoblasts in a low oxygen tension environment greatly reduced their invasiveness.

These data indicate that hypoxia changes the balance between proliferation and differentiation in cytotrophoblasts. With regard to the cell cycle, our results are in agreement with decades-old morphological studies that describe marked proliferation of the cytotrophoblast layer in tissue sections of placentas from pregnancies complicated by preeclampsia (44), a finding that has recently been confirmed (12). Similarly, culturing chorionic villi under hypoxic conditions has been reported to result in cytotrophoblast proliferation (45), although this result has not been replicated (46). Whether oxygen tension affects passage through the cell cycle in other cells has not been widely studied. Limited evidence suggests the observed effects are cell-type specific. For example, hypoxia induces proliferation of vascular smooth muscle cells $(47,48)$, but leads to $G_{1}$ arrest in a variety of tumor cell lines (49). Likewise, hypoxia stimulates differentiation of erythrocytes (via induction of erythropoietin; 50) but inhibits that of 3T3-L1 fibroblasts (51).

Our findings also suggest that hypoxia changes the cells' expression of integrin $\alpha 1$, which is a stage-specific marker of cytotrophoblast differentiation. The effects of hypoxia on adhesion molecule expression in other systems are beginning to be studied. For example, cultured human umbilical vein endothelial cells subjected to low oxygen tension upregulate, after reoxygenation, endothelial-leukocyte adhesion molecule- 1 and intercellular adhesion molecule-1 expression (26, 52). Conse- 

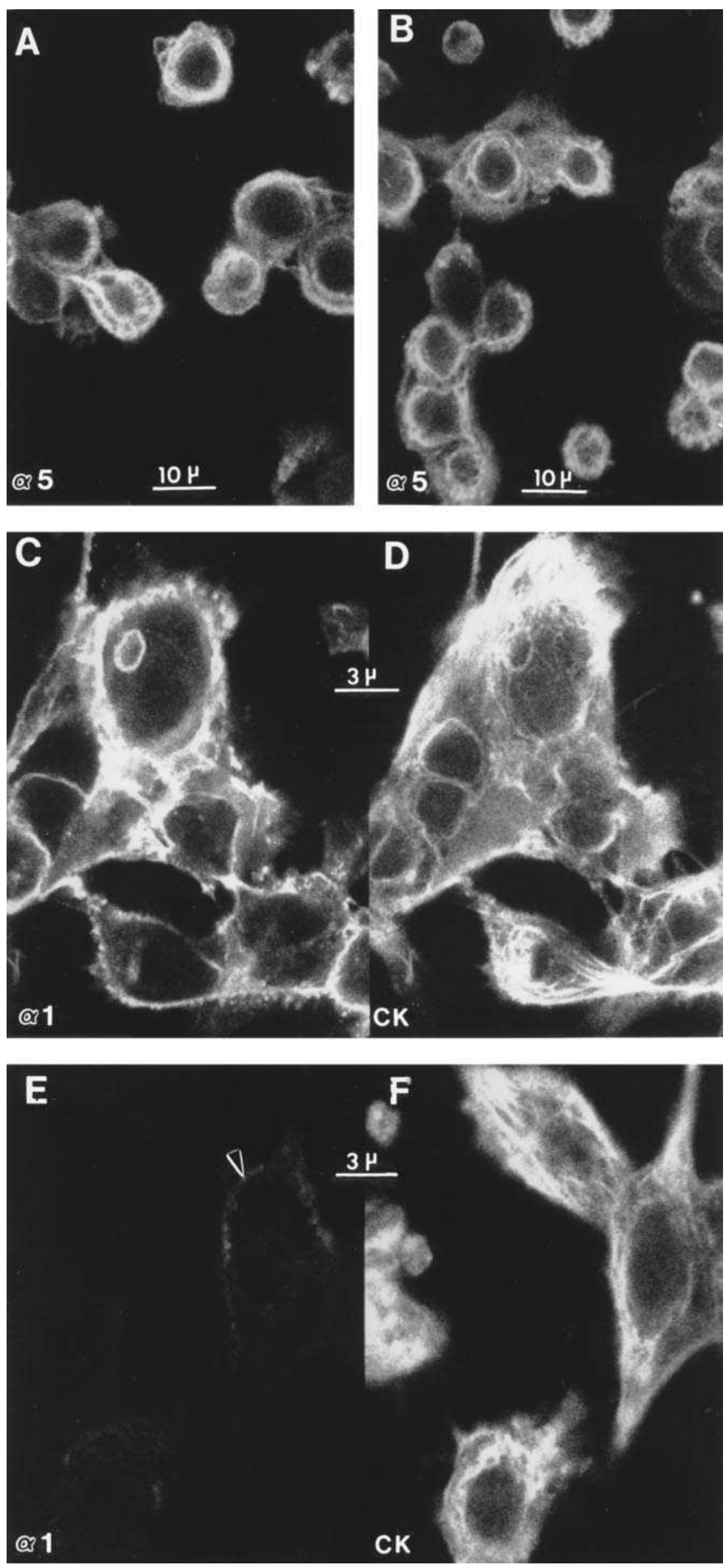

Figure 7. Hypoxia alters cytotrophoblast integrin expression. Isolated 10-12 wk cytotrophoblasts were plated on Matrigel-coated Transwell filters and cultured in 20 or $2 \%$ oxygen for $72 \mathrm{~h}$. The cells were double stained with antibodies that recognized cytokeratin $(C K)$ and either $\alpha 5$ or $\alpha 1$, two integrin subunits whose expression is upregulated during differentiation along the invasive pathway in vivo (3) and in vitro (9). Then the filters were removed from the inserts and mounted on slides such that the original Matrigel-coated surface faced upward. Integrin expression was analyzed by confocal microscopy. Greater than $98 \%$ of the cells cultured in either $2 \%(A)$ or $20 \%(B)$ oxygen reacted with the anti- $\alpha 5$ antibody. A similar percentage of cytotrophoblasts cultured in $20 \%$ oxygen upregulated integrin $\alpha 1$ expression $(C)$. In contrast, the majority of cells that had been cultured in $2 \%$ oxygen did not react with the anti- $\alpha 1$ antibody $(E)$. Often only weak reactivity was detected (arrowhead). The fact that the cells were cytotrophoblasts was verified by colocalizing integrin $\alpha 1$ and cytokeratin $(C K)$ expression $(D$ and $F)$. 
quently, there is a severalfold increase in the number of leukocytes that adhere, in a leukocyte function antigen (LFA)-1dependent mechanism, to the reoxygenated human umbilical vein endothelial cell monolayers $(52,53)$. These results help explain why hypoxia leads to increases in leukocyte-blood vessel adhesive interactions. LFA-1 also mediates increased leukocyte adhesion to human muscle cells subjected to a low oxygen tension environment. In this case, intercellular adhesion due to vascular cell adhesion molecule-1 interactions with LFA-4 is simultaneously downregulated (53).

The concept that oxygen tension regulates cytotrophoblast differentiation has several interesting implications with regard to the interplay between physiology and placental development in normal pregnancy. The experiments described in this paper primarily focused on differentiation of cytotrophoblasts isolated from 10-12 wk human placentas. This time period is an important physiological transition in pregnancy during which blood flow to the placenta substantially increases. Morphological studies of the placental bed show that throughout much of the first trimester, cytotrophoblast invasion is confined to the terminal portions of uterine blood vessels near the uterine lumen (3). Ex vivo angiography of hysterectomy specimens (54) and in vivo color Doppler imaging (55) show no evidence of blood flow to the intervillous space during this same time period. During the second trimester of pregnancy, endovascular invasion proceeds rapidly, and these vessels are transformed into wide-bore, low-resistance, high-capacity channels.

Our data suggest that this physiological transition coincides with an important transition in placental development, namely the point at which cytotrophoblast differentiation along the invasive pathway becomes sensitive to hypoxia. Since we cannot obtain enough placental tissue to study the isolated cells before $8 \mathrm{wk}$ gestation, we are using another invasion/differentiation model, explanting anchoring villi to Matrigel, for this purpose (42). These experiments show that before $7 \mathrm{wk}$ gestation, hypoxia does not inhibit cytotrophoblast invasion (Genbacev, O., and S. J. Fisher, manuscript in preparation); such inhibition appears at $\sim 10$ wk gestation. These data are in accord with the results described here which show that hypoxia arrests cytotrophoblasts isolated from 10-12 wk placentas in the initial stages of differentiation along the invasive pathway. Thus, we hypothesize that during early pregnancy, allocation of the trophoblast lineage and differentiation/invasion can occur in a relatively hypoxic environment. However, normal placental development after the first trimester of pregnancy requires that the cytotrophoblast subpopulation that lies at the maternal-fetal interface has an adequate supply of maternal blood. Thus, our work adds new information as to why the uterine vascular changes that occur at the end of the first trimester and that substantially increase blood flow to the maternal-fetal interface are critical to the outcome of pregnancy.

With regard to abnormal placental development, we hypothesize that when cytotrophoblasts do not access an adequate maternal blood supply, they survive because they are relatively resistant to hypoxia. However, the cells are less able to invade, thus setting up the series of events that results in shallow placentation and, by some unknown mechanism, initiates the preeclampsia syndrome. The fact that we can duplicate the abnormalities in cytotrophoblast differentiation that occur in preeclampsia by culturing normal cells in a hypoxic environment suggests that the placental defects associated with this syndrome can be at least partially attributed to de- creased placental perfusion and that this is an important proximal event in the chain of events that leads to this disease.

\section{Acknowledgments}

We thank Ms. Evangeline Leash for editing the manuscript.

This work was supported by National Institutes of Health grants HD 30367 and HD 22210 and by grant 3 RT-0324 from the University of California Tobacco-related Disease Research Program.

\section{References}

1. Fisher, S. J., and C. H. Damsky. 1993. Human cytotrophoblast invasion. Semin. Cell Biol. 4:183-188.

2. Cross, J. C., Z. Werb, and S. J. Fisher. 1994. Implantation and the placenta: key pieces of the development puzzle. Science (Wash. DC). 266:15081518 .

3. Damsky, C. H., M. L. Fitzgerald, and S. J. Fisher. 1992. Distribution patterns of extracellular matrix components and adhesion receptors are intricately modulated during first trimester cytotrophoblast differentiation along the invasive pathway in vivo. J. Clin. Invest. 89:210-222.

4. Polette, M., B. Nawrocki, A. Pintiaux, C. Massenat, E. Maquoi, L. Volders, J. P. Schaaps, P. Birembaut, and J. M. Foidart. 1994. Expression of gelatinases $\mathrm{A}$ and $\mathrm{B}$ and their tissue inhibitors by cells of early and term human placenta and gestational endometrium. Lab. Invest. 71:838-846.

5. Fisher, S. J., T. Y. Cui, L. Zhang, L. Hartman, K. Grahl, G. Y. Zhang, J. Tarpey, and C. H. Damsky. 1989. Adhesive and degradative properties of human placental cytotrophoblast cells in vitro. J. Cell Biol. 109:891-902.

6. Librach, C. L., Z. Werb, M. L. Fitzgerald, K. Chiu, N. M. Corwin, R. A. Esteves, D. Grobelny, R. Galardy, C. H. Damsky, and S. J. Fisher. 1991. 92-kD type IV collagenase mediates invasion of human cytotrophoblasts. J. Cell Biol. 113:437-449.

7. Librach, C. L., S. L. Feigenbaum, K. E. Bass, T. Cui, N. Verastas, Y. Sadovsky, J. P. Quigley, D. L. French, and S. J. Fisher. 1994. Interleukin-1ß regulates human metalloproteinase activity and invasion in vitro. J. Biol. Chem. 269: 17125-17131.

8. Bass, K. E., D. Morrish, I. Roth, D. Bhardwaj, R. Taylor, Y. Zhou, and S. J. Fisher. 1994. Human cytotrophoblast invasion is up-regulated by epidermal growth factor: evidence that paracrine factors modify this process. Dev. Biol. 164:550-561.

9. Damsky, C. H., C. L. Librach, K. H. Lim, M. L. Fitzgerald, M. T. McMaster, M. Janatpour, Y. Zhou, S. K. Logan, and S. J. Fisher. 1994. Integrin switching regulates normal trophoblast invasion. Development (Camb.). 120:36573666 .

10. McMaster, M. T., C. L. Librach, Y. Zhou, K.-H. Lim, M. J. Janatpour, R. DeMars, S. Kovats, C. H. Damsky, and S. J. Fisher. 1995. Human placental HLA-G expression is limited to differentiated cytotrophoblasts. J. Immunol. 154:3771-3778.

11. Roberts, J. M., R. N. Taylor, S. A. Friedman, and A. Goldfien. 1990. New developments in pre-eclampsia. In Fetal Medical Review. W. Dunlop, editor. Edward Arnold Publishers, London. 125-141.

12. Redline, R. W., and P. Patterson 1995. Pre-eclampsia is associated with an excess of proliferative, immature intermediate trophoblasts. Human Pathol. 26:594-600.

13. Lunell, N. O., L. E. Nylund, R. Lewander, and B. Sarby. 1982. Uteroplacental blood flow in pre-eclampsia measurements with indium-113m and a computer-linked gamma camera. Clin. Exp. Hypertens. 1:105-117.

14. Redman, C. W. 1991. Current topic: pre-eclampsia and the placenta. Placenta. 12:301-308.

15. Zhou, Y., C. H. Damsky, K. Chiu, J. M. Roberts, and S. J. Fisher. 1993. Preeclampsia is associated with abnormal expression of adhesion molecules by invasive cytotrophoblasts. J. Clin. Invest. 91:950-960.

16. Lim, K.-H., K. Bass, S.-H. Chun, C. H. Damsky, and S. J. Fisher. 1994 Differentiation of invasive cytotrophoblasts in normal and abnormal pregnancy. Soc. Gynecol. Invest. 42:107a (Abstr.)

17. Anderson, G. R., D. L. Stoler, and L. A. Scarcello. 1989. Normal fibroblasts responding to anoxia exhibit features of the malignant phenotype. J. Biol. Chem. 264:14885-14892.

18. Heacock, C. S., and R. M. Sutherland. 1986. Induction characteristics of oxygen regulated proteins. Int. J. Radiat. Oncol. Biol. Phys. 12:1287-1290.

19. Sciandra, J. J., J. R. Subjeck, and C. S. Hughes. 1984. Induction of glucose-regulated proteins during anaerobic exposure and of heat-shock proteins after reoxygenation. Proc. Natl. Acad. Sci. USA. 81:4843-4847.

20. Vass, K., W. J. Welch, and T. J. Nowak. 1988. Localization of 70-kDa stress protein induction in gerbil brain after ischemia. Acta Neuropathol. 77: $128-135$.

21. Gething, M. J., and J. Sambrook. 1992. Protein folding in the cell. Nature (Lond.). 355:33-45.

22. Beru, N., J. McDonald, C. Lacombe, and E. Goldwasser. 1986. Expres- 
sion of the erythropoietin gene. Mol. Cell. Biol. 6:2571-2575.

23. Bondurant, M. C., and M. J. Koury. 1986. Anemia induces accumulation of erythropoietin mRNA in the kidney and liver. Mol. Cell. Biol. 6:2731-2733.

24. Kourembanas, S., R. L. Hannan, and D. V. Faller. 1990. Oxygen tension regulates the expression of the platelet-derived growth factor-B chain gene in human endothelial cells. J. Clin. Invest. 86:670-674.

25. Kourembanas, S., P. A. Marsden, L. P. McQuillan, and D. V. Faller. 1991. Hypoxia induces endothelin gene expression and secretion in cultured human endothelium. J. Clin. Invest. 88:1054-1057.

26. Shreeniwas, R., S. Koga, M. Karakurum, D. Pinsky, E. Kaiser, J. Brett, B. A. Wolitzky, C. Norton, J. Plocinski, W. Benjamin, et al. 1992. Hypoxiamediated induction of endothelial cell interleukin-1 alpha. An autocrine mechanism promoting expression of leukocyte adhesion molecules on the vessel surface. J. Clin. Invest. 90:2333-2339.

27. Karakurum, M., R. Shreeniwas, J. Chen, D. Pinsky, S. D. Yan, M. Anderson, K. Sunouchi, J. Major, T. Hamilton, K. Kuwabara, et al. 1994. Hypoxic induction of interleukin-8 gene expression in human endothelial cells. $J$. Clin. Invest. 93:1564-1570.

28. Longo, L. D., S. Packianathan, J. A. McQueary, R. B. Stagg, C. V. Byus, and C. D. Cain. 1993. Acute hypoxia increases ornithine decarboxylase activity and polyamine concentrations in fetal rat brain. Proc. Natl. Acad. Sci. USA. 90: 692-696.

29. Shweiki, D., A. Itin, D. Soffer, and E. Keshet. 1992. Vascular endothelial growth factor induced by hypoxia may mediate hypoxia-initiated angiogenesis. Nature (Lond.). 359:843-845.

30. Graven, K. K., R. F. Troxler, H. Kornfeld, M. V. Panchenko, and H. W. Farber. 1994. Regulation of endothelial cell glyceraldehyde-3-phosphate dehydrogenase expression by hypoxia. J. Biol. Chem. 269:24446-24453.

31. Hassoun, P. M., F. S. Yu, A. L. Shedd, J. J. Zulueta, V. J. Thannickal, J. J. Lanzillo, and B. L. Fanburg. 1994. Regulation of endothelial cell xanthine dehydrogenase and xanthine oxidase gene expression by oxygen tension. Am.J. Physiol. L163-L171.

32. Murphy, B. J., K. R. Laderoute, R. J. Chin, and R. M. Sutherland. 1994. Metallothionein IIA is up-regulated by hypoxia in human A431 squamous carcinoma cells. Cancer Res. 54:5808-5810.

33. Semenza, G. L., and G. L. Wang. 1992. A nuclear factor induced by hypoxia via de novo protein synthesis binds to the human erythropoietin gene enhancer at a site required for transcriptional activation. Mol. Cell. Biol. 12:54475454.

34. Wang, G. L., and G. L. Semenza. 1993. General involvement of hypoxia-inducible factor 1 in transcriptional response to hypoxia. Proc. Natl. Acad. Sci. USA. 90:4304-4308.

35. Semenza, G. L., P. H. Roth, H. M. Fang, and G. L. Wang. 1994. Transcriptional regulation of genes encoding glycolytic enzymes by hypoxia-inducible factor 1. J. Biol. Chem. 269:23757-23763.

36. Webster, K. A., D. J. Discher, and N. H. Bishopric. 1993. Induction and nuclear accumulation of fos and jun proto-oncogenes in hypoxic cardiac myocytes. J. Biol. Chem. 268:16852-16858.

37. Koong, A. C., E. Y. Chen, and A. J. Giaccia. 1994. Hypoxia causes the activation of nuclear factor kappa B through the phosphorylation of I kappa B alpha on tyrosine residues. Cancer Res. 54:1425-1430.

38. Benjamin, I. J., B. Kroger, and R. S. Williams. 1990. Activation of the heat shock transcription factor by hypoxia in mammalian cells. Proc. Natl. Acad. Sci. USA. 87:6263-6267.
39. Rodesch, F., P. Simon, C. Donner, and E. Jauniaux. 1992. Oxygen measurements in endometrial and trophoblastic tissues during early pregnancy. $\mathrm{Ob}$ stet. Gynecol. 80:283-285.

40. Charbonneau, H., N. K. Tonks, S. Kumar, C. D. Diltz, M. Harrylock, D. E. Cool, E. G. Krebs, E. H. Fischer, and K. A. Walsh. 1989. Human placenta protein-tyrosine-phosphatase: amino acid sequence and relationship to a family of receptor-like proteins. Proc. Natl. Acad. Sci. USA. 86:5252-5256.

41. Kovats, S., C. Librach, P. Fisch, E. K. Main, P. M. Sondel, S. J. Fisher, and R. DeMars. 1991. Expression and possible function of the HLA-G a chain in human cytotrophoblasts. In Cellular and Molecular Biology of the MaternoFetal Relationship. Vol. 212. G. Chaouat, and J. Mowbray, editors. John Libbey Eurotext Ltd., New York. 21-29.

42. Genbacev, O., S. A. Schubach, and R. K. Miller. 1992. Villous culture of first trimester human placenta-model to study extravillous trophoblast (EVT) differentiation. Placenta. 13:439-461.

43. Genbacev, O., S. S. Powlin, and R. K. Miller. 1994. Regulation of human extravillus trophoblast (EVT) cell differentiation and proliferation in vitro. Role of epidermal growth factor (EGF). Troph. Res. 8:427-442.

44. Fox, H. 1964. The villous cytotrophoblast as an index ischaemia. $J$. $O b$ stet. Gynaecol. Br. Commonw. 71:885-893.

45. Tominaga, T., and E. W. Page. 1966. Accommodation of the human placenta to hypoxia. Am. J. Obstet. Gynecol. 94:679-691.

46. Burton, G. J., T. M. Mayhew, and L. A. Robertson. 1989. Stereological re-examination of the effects of varying oxygen tensions on human placental villi maintained in organ culture for up to $12 \mathrm{~h}$. Placenta. 10:263-273.

47. Butler, A. J., M. J. Eagleton, D. Wang, R. L. Howell, A. R. Strauch, V. Khasgiwala, and H. C. Smith. 1991. Induction of the proliferative phenotype in differentiated myogenic cells by hypoxia. J. Biol. Chem. 266:18250-18258.

48. Dempsey, E. C., I. F. McMurtry, and R. F. O'Brien. 1991. Protein kinase $\mathrm{C}$ activation allows pulmonary artery smooth muscle cells to proliferate to hypoxia. Am. J. Physiol. 260:L136-L145.

49. Graeber, T. G., J. F. Peterson, M. Tsai, K. Monica, A. J. Fornace, and A. J. Giaccia. 1994. Hypoxia induces accumulation of p53 protein, but activation of a G1-phase checkpoint by low-oxygen conditions is independent of p53 status. Mol. Cell. Biol. 14:6264-6277.

50. Goldberg, M. A., C. C. Gaut, and H. F. Bunn. 1991. Erythropoietin mRNA levels are governed by both the rate of gene transcription and posttranscriptional events. Blood. 77:271-277.

51. Sahai, A., M. S. Patel, A. S. Zavosh, and R. L. Tannen. 1994. Chronic hypoxia impairs the differentiation of 3T3-L1 fibroblast in culture: role of sustained protein kinase C activation. J. Cell. Physiol. 160:107-112.

52. Arnould, T., C. Michiels, and J. Remacle. 1993. Increased PMN adherence on endothelial cells after hypoxia: involvement of PAF, CD18/CD11b, and ICAM-1. Am. J. Physiol. C1102-C1110.

53. Ginis, I., S. J. Mentzer, and D. V. Faller. 1993. Oxygen tension regulates neutrophil adhesion to human endothelial cells via an LFA-1-dependent mechanism. J. Cell. Physiol. 157:569-578.

54. Hustin, J., and J. P. Schaaps. 1987. Echographic [corrected] and anatomic studies of the maternotrophoblastic border during the first trimester of pregnancy [published erratum appears in Am. J. Obstet. Gynecol. 1987. 157: 1291]. Am. J. Obstet. Gynecol. 157:162-168.

55. Jaffe, R., and J. J. Woods. 1993. Color Doppler imaging and in vivo assessment of the anatomy and physiology of the early uteroplacental circulation. Fertil. Steril. 60:293-297. 